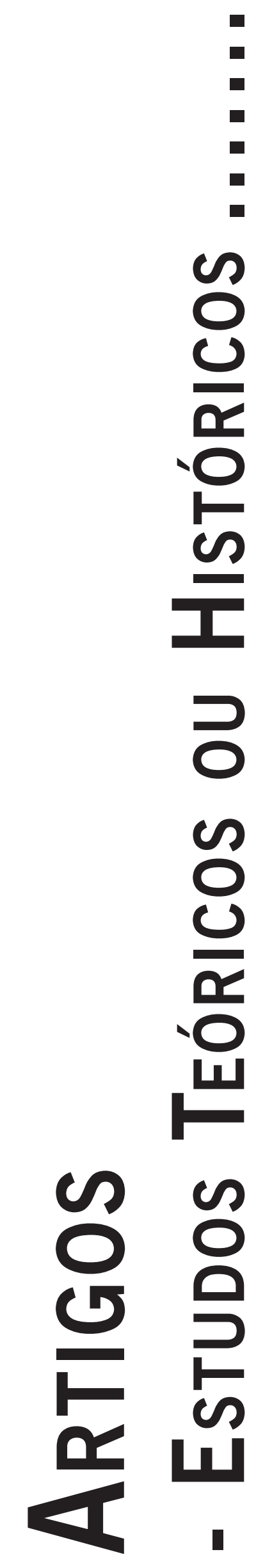




\title{
NISE DA SILVEIRA E O ENFOQUE FENOMENOLÓGICO
}

\author{
Nise da Silveira and the Phenomenological Approach \\ Nise da Silveira y el Enfoque Fenomenológico
}

Karoline Stoltz Schleder

\begin{abstract}
Resumo: O objetivo desta pesquisa é promover um diálogo entre o trabalho da psiquiatra brasileira Nise da Silveira (1905-1999) e o pensamento fenomenológico. Embora Nise da Silveira não tenha se envolvido diretamente a fenomenologia, seu trabalho, concepção de sujeito e postura frente aos pacientes ali encontram eco. Trata-se de um estudo bibliográfico-qualitativo, no qual foi realizada revisão de literatura nas bases de dados SciELO, PePSIC e LILACS, além da análise de bibliografias primárias e secundárias de Nise da Silveira. Foram encontradas 13 bibliografias primárias e 20 bibliografias secundárias, sendo 13 referentes a revisão de literatura. A maior parte do material bibliográfico reflete sobre a prática pioneira de Nise da Silveira com esquizofrênicos na Seção de Terapêutica Ocupacional, no hospital de Engenho de Dentro, no Museu Imagens do Inconsciente ou na Casa das Palmeiras e a reconhece como uma das precursoras do movimento da antipsiquiatria no Brasil. Sua valorização da prática; ênfase na observação do sujeito em seu contexto, para além de sua psicopatologia; além da defesa da potencialidade terapêutica do trabalho com animais, da expressão criativa e a importância da empatia, apontam para uma posição muito próxima da atitude fenomenológica: coloca a doença entre parênteses, para compreender a esquizofrenia como um dos modos possíveis de ser no mundo. Palavras-chave: Nise da Silveira; Fenomenologia; História da psicologia.
\end{abstract}

\begin{abstract}
The aim of this study is to promote a dialogue between the work of Brazilian psychiatrist Nise da Silveira (1905-1999) and the phenomenological approach. Although Nise da Silveira was not directly involved with phenomenology, her work, concept of subject and attitude toward patients are similar. This is a bibliographic-qualitative study in which a literature review was conducted using SciELO, LILACS and PePSIC databases, in addition to analysis of primary and secondary bibliographies on Nise da Silveira. 13 primary and 20 secondary bibliographies were found, 13 are related to the literature review in the databases. Most of the bibliography reflects on Nise da Silveira's pioneer work with schizophrenic patients at the Occupational Therapy Section, at the Engenho de Dentro Hospital, at the Imagens do Inconsciente Museum and at the Casa das Palmeiras and recognizes her as one of the forerunners of the anti-psychiatry movement in Brazil. Her appreciation of practice; emphasis on observation of subjects in their own context, beyond psychopathology; in addition to the defense of the therapeutic potential of working with animals, creative expression and the importance of empathy, point to a position very close to the phenomenological attitude: it places brackets around illness, in order to understand schizophrenia as one of the possible ways of being in the world.
\end{abstract}

Keywords: Nise da Silveira; Phenomenology; History of psychology.

Resumen: El objetivo de esta investigación es establecer un diálogo entre el trabajo de la psiquiatra brasileña Nise da Silveira (1905-1999) y el pensamiento fenomenológico. Aunque Nise da Silveira no se haya involucrado directamente con la fenomenología, en ella hace eco su trabajo sobre concepción de sujeto y postura frente a los pacientes. Por lo tanto, este es un estudio bibliográfico-cualitativo, en el que se realizó una revisión de literatura en las bases de datos SciELO, PePSIC y LILACS, además del análisis de bibliografías primarias y secundarias de Nise da Silveira. Fueron encontradas 13 bibliografias primarias y 20 bibliografías secundarias, siendo que de las 20, 13 están relacionadas con la revisión de literatura en las bases de datos. Gran parte del material bibliográfico refleja la práctica pionera de Nise da Silveira con esquizofrénicos en la Seção de Terapêutica Ocupacional, en el hospital de Engenho de Dentro, en el Museu Imagens do Inconsciente o en la Casa das Palmeiras, y la reconoce como una de las precursoras del movimiento de la antipsiquiatría en Brasil. Su valoración hacia la práctica; el énfasis en la observación del sujeto en su contexto, por lo tanto más allá de su psicopatología - además de la defensa de la potencialidad terapéutica del trabajo con animales, de la expresión creativa y de la importancia de la empatía - es lo que alude su actitud fenomenológica: la investigadora deja la enfermedad a un lado para comprender la esquizofrenia como uno de los modos posibles de ser en el mundo. Palabras clave: Nise da Silveira; Fenomenología; Historia de la psicología.

\section{Introdução}

Nise da Silveira (1905-1999) foi uma grande personalidade da psiquiatria brasileira e é também considerada uma das pioneiras da psicologia no Brasil. É reconhecida como uma das precursoras do movimento da antipsiquiatria por sua postura diferenciada frente aos seus pacientes (Silveira, 1992a, 1986; Melo, 2001a, 2001b, 2010a, 2010b; Mello, 2005, 2009a, 2009b) e é considerada uma das mulheres pioneiras da ciência no Brasil (Melo \& Rodrigues, 2006).

Nascida em Maceió, filha do professor de matemática e jornalista Faustino Magalhães e da pianista Maria Lidia da Silveira, Nise cursou a faculdade de Medicina 
da Bahia, formando-se em 1926. Neste tempo, passou a viver junto com o médico sanitarista Mario Magalhães, seu primo, com o qual concluiu o curso de Medicina. Em 1927, se mudaram para o Rio de Janeiro e, em 1933, Nise da Silveira ingressou como médica psiquiatra no Serviço de Assistência a Psicopatas e Profilaxia Mental do Hospital da Praia Vermelha. Ali mesmo, em 1936, foi presa durante a Intentona Comunista, permanecendo 15 meses na prisão. Foi apenas em 1944 que Nise da Silveira retornou ao serviço público, passando a trabalhar no antigo Centro Psiquiátrico Nacional de Engenho de Dentro (o atual Instituto Municipal Nise da Silveira). Inconformada com o tratamento psiquiátrico da época, criou a Seção de Terapêutica Ocupacional no Centro Psiquiátrico, em 1946, fazendo com que este campo ganhasse repercussão internacional (Arruda, 1995).

A partir daí, iniciou aqueles trabalhos pelos quais é mais conhecida: em 1952 fundou o Museu Imagens do Inconsciente (Silveira, 1992a), com obras de seus pacientes e, em continuação, em 1956, criou a pioneira clínica psiquiátrica de regime aberto, conhecida como a Casa das Palmeiras (Silveira, 1986), com o intuito de funcionar como intermediária entre a rotina do sistema hospitalar, desindividualizada, e a vida na sociedade. Buscando compreender o que se passava com seus clientes por meio da expressão artística, estudou a psicologia analítica e esteve no Instituto Carl Gustav Jung, em 1957-1958 e 1961-1962, tornando-se referência da abordagem teórica no Brasil (Melo, 2001a, 2001b, 2007; Mello, 2005, 2009a). Nise da Silveira faleceu aos 94 anos, no Rio de Janeiro.

Seu legado foi de poucas publicações, abordando seus trabalhos desenvolvidos na Seção de Terapêutica Ocupacional e Reabilitação, no Museu de Imagens do Inconsciente e na Casa das Palmeiras, também sobre terapia ocupacional e a psicologia analítica de C.G.Jung, além de estudos sobre a filosofia de Spinoza entre outras temáticas que permearam sua praxis. O Dicionário Biográfico da Psicologia no Brasil cita 16 publicações da autora, em sua maioria livros (Melo, 2001a). Dispõe-se hoje também de bibliografia secundária sobre Nise da Silveira, na forma de livros e artigos científicos que permitem melhor apreender o pensamento da psiquiatra, a partir de sua prática (Melo, 2001a, 2001b, 2007, 2010a, 2010b; Frayze-Pereira, 2003; Motta, 2005; Castro \& Lima, 2007; Figueira, Amarante \& Belancieiri, 2007; Guimarães \& Saeki, 2007; Mello, 2009a, 2009b). Entretanto, percebe-se que ainda há pouca divulgação e dificuldade de acesso ao trabalho de Nise da Silveira.

Mesmo sendo remetido a Nise da Silveira o pioneirismo em relação à psicologia e reforma psiquiátrica no Brasil, observam-se poucos estudos sobre seu trabalho e nenhuma pesquisa que se proponha a estabelecer um diálogo entre Nise da Silveira e a psicologia fenomenológico-existencial. Assim, o presente artigo tem como objetivo promover um diálogo entre o trabalho desenvolvido por Nise da Silveira e a psicologia fenomenológico-existencial, traçando possíveis proximidades e divergências.

\section{Método}

Este é um estudo bibliográfico-qualitativo, no qual foi realizada revisão de literatura em bases de dados e análise de bibliografias primárias e secundárias de Nise da Silveira, além de análise de bibliografias da psicologia fenomenológico-existencial.

Primeiramente, de modo a investigar especificamente a produção acadêmica atual sobre Nise da Silveira, foi realizada revisão de literatura nas bases de dados SciELO (Scientific Eletronic Library Online), PePSIC (Periódicos Eletrônicos em Psicologia) e LILACS (Literatura LatinoAmericana e do Caribe em Ciências da Saúde). Optou-se por tais bases de dados, por contemplarem vasta quantidade de publicações na área da psicologia. Os indexadores foram NISE e SILVEIRA, sem refinamento. Por meio da análise dos resumos, foram desconsideradas as referências que não tratavam de Nise da Silveira. Referências primárias também foram desconsideradas nesta primeira análise, pois a intenção era observar a repercussão de seu trabalho na literatura contemporânea. Posteriormente, executou-se análise qualitativa comparativa das referências encontradas.

Num segundo momento, foram realizadas considerações acerca da psicologia fenomenológico-existencial, tendo por referencial e ponto de partida, a figura de Edmund Husserl, fundador da fenomenologia e comentadores de sua obra na língua portuguesa (Husserl, 1929/1992; Dartigues, 2005; Bello, 2006; Depraz, 2007). Posteriomente, executou-se pesquisa e análise de referências primárias e secundárias sobre Nise da Silveira, além das encontradas na revisão de literatura nas bases de dados. Discutiu-se a possibilidade de estabelecer similaridades e divergências entre o trabalho desenvolvido por Nise da Silveira e a abordagem fenomenológico-existencial.

\section{Atualidade do pensamento de Nise da Silveira}

Na revisão de literatura nas bases de dados, foram encontradas inicialmente 25 referências, sem repetição, Destas, 18 referências (nove artigos, dois livros, duas dissertações, um depoimento, uma biografia, uma cartilha de monitoria, um catálogo de vídeo e uma entrevista) diziam respeito a Nise da Silveira. Por ser referência primária, a entrevista (Leal, 1994) foi desconsiderada nesta primeira análise. Ao todo, foi possível acessar 13 referências para a revisão de literatura nas bases de dados citadas nove artigos, dos quais um destes somente se teve acesso ao resumo (Motta, 2005), um depoimento, um livro, uma dissertação e uma biografia. Não foi possível acessar as seguintes publicações: Terapias expressivas: uma pesquisa de referenciais teórico-práticos (Andrade, 1993); Nise da Silveira: vida e obra: catálogo de vídeos (Ministério da Saúde, 2007a) e Nise da Silveira: vida e obra: cartilha de monitoria (Ministério da Saúde, 2007b); além de $O$ an- 
tídoto do mal: crítica de arte e loucura na modernidade brasileira (Dionísio, 2012).

As bibliografias acessadas na revisão nas bases de dados são todas produções científicas brasileiras datadas majoritariamente da primeira década do século XXI, havendo maior concentração de publicações de trabalhos em 2007. Não há uma concentração de publicações em revista específica. Isso indica um interesse mais geral pelo trabalho de Nise da Silveira, sem um enfoque de uma perspectiva teórica específica. Além disso, observa-se que Walter Melo (2001b, 2007, 2010a, 2010b) é autor de parte significativa da produção científica disponível sobre Nise da Silveira.

Com exceção de Karniol (2003), que descreve sua experiência no tratamento de esquizofrênicos por meio da psicanálise, reconhecendo a proximidade de seu trabalho com o de Nise da Silveira, na possibilidade de comunicação com os pacientes por meio da arte, as publicações científicas são compostas por estudos teóricos acerca de determinadas fases do trabalho ou temáticas abordadas por Nise da Silveira. Há maior incidência de trabalhos abordando Nise da Silveira como uma das pioneiras da reforma psiquiátrica no Brasil (Estrada, 1995; Motta, 2005; Melo, 2007, 2010a, 2010b; Castro \& Lima, 2007; Figueira, Amarante \& Belancieiri, 2007).

Segundo Figueira, Amarante \& Belancieiri (2007), o Museu de Imagens do Inconsciente, idealizado pela psiquiatra, faz parte da história da reforma psiquiátrica. Nise da Silveira também é apontada como referência nos estudos de psicologia analítica de Jung no país (Melo, 2001b, 2007; Nise da Silveira, 2002; Motta, 2005). Entretanto, Estrada (1995) comenta que isso não significa que Nise da Silveira tenha simplesmente aplicado a teoria de Jung: "Ela insiste em afirmar que não teve formação junguiana e que para ela Jung foi um instrumento de trabalho" (p. 210).

Alguns autores indicam uma indissociabilidade entre arte, sociedade e política no seu trabalho, como apontam Frayze-Pereira (2003), a partir da análise do Museu de Imagens do Inconsciente; e Melo (2010a), quando analisa um filme sobre o tratamento de Fernando Diniz, que foi paciente da psiquiatra. Para Dias (2003), que em sua tese de mestrado estuda o processo de transformação dos ateliês de Nise da Silveira no Museu Imagens do Inconsciente, fundado em 1952, a aceitação de suas ideias foi possibilitada pela emergência do discurso psicanalítico no Brasil. A autora também afirma que nesse período, o ambiente artístico foi fundamental para apoiar esse trabalho da psiquiatra, já que não possuía atenção do contexto científico da época. Segundo Frayze-Pereira (2003), o Museu Imagens do Inconsciente não só foi construído a partir da perspectiva teórica da psicologia junguiana, mas também pela influência de outros autores, como o poeta francês Antonin Artaud e críticos de arte, com os quais Nise da Silveira estabeleceu contato.

O Museu Imagens do Inconsciente apresentava coleção de imagens produzidas pelos pacientes de Nise da Silveira, que frequentavam os ateliês de pintura e escul- tura do hospital Engenho de Dentro. Para Frayze-Pereira (2003), a dificuldade do Museu de se manter, se estabeleceu também por ter se tornado ameaçador para a manutenção das instituições disciplinares que, ao contrário de possibilitar a livre expressão de seus pacientes, são voltadas para a anestesia da sensibilidade. Nise da Silveira indagava sobre a exclusão social dos sujeitos internados nos manicômios, devolvendo-lhes, por meio da arte, a possibilidade de se expressar (Estrada, 1995; Melo, 2001b, 2010a, 2010b; Castro \& Lima, 2007). Dizia a psiquiatra: "Mas eu não examinava as pinturas dos doentes que frequentavam nosso atelier sentada no meu gabinete. Eu os via pintar. Via suas faces crispadas, via o ímpeto que movia suas mãos" (Nise da Silveira, citada por Melo, 2010a, p. 639). Foi nesta direção que a psiquiatra propunha as atividades do museu, como um "museu vivo" (Melo, 2001b; Frayze-Pereira, 2003).

Para Melo (2010a), a postura de Nise da Silveira, ao se contrapor à psiquiatria clássica, valorizou o conteúdo em detrimento da forma no processo de expressão artística de seus pacientes, partindo do que eles experienciavam (Castro \& Lima, 2007; Melo, 2010b). "Arte é o catalisador por excelência das aproximações de opostos. Por seu intermédio, sensações, emoções, pensamentos, são levados a reconhecerem-se entre si, a associarem-se, e mesmo tumultos internos adquirem forma" (Castro \& Lima, 2007, p. 367). Além disso, sob a perspectiva junguiana, Nise da Silveira compreende que a pintura é instrumento de expressão do paciente para reorganizar seu mundo interno e a relação com o mundo exterior.

Guimarães \& Saeki (2007) discutem sobre a temporalidade no hospital psiquiátrico, caracterizado pela desconsideração do tempo vivido. Nise da Silveira, segundo as autoras, observou a necessidade de considerar o afeto na terapêutica hospitalar, buscando resgatar a ligação entre ele e as vivências de tempo do doente. Para isso, intervia no resgate da dignidade dos seus pacientes, acolhendo-os e chamando-os pelo nome. Segundo Melo (2001b) e Motta (2005), a psiquiatra desenvolve um tratamento novo, embasado no afeto, o qual nomeou "emoções de lidar”. Estrada (1995) e Castro \& Lima (2007) também observam que Nise da Silveira se envolveu no trabalho com os psicóticos, deixando-se afetar por eles, criando um ambiente acolhedor nas oficinas terapêuticas, nas quais os monitores deveriam ser catalisadores do afeto de seus pacientes para que desenvolvessem a criatividade.

Além disso, Castro \& Lima (2007) e Melo (2010a; 2010b), em estudo sobre José, primeiro cliente da Casa das Palmeiras, afirmam que a terapêutica desenvolvida por Nise da Silveira se fundamenta na livre expressão de seus clientes. "Muda-se, desta forma, a concepção de uma doença que precisa ser controlada à força para a possibilidade de expressão do ser" (Melo, 2010b, p. 867). Estrada (1995), Melo (2001b) e Castro \& Lima (2007) afirmam que para Nise da Silveira, a psicopatologia consiste em diferentes modos de existência do sujeito, de estar no 
mundo. Estrada (1995) afirma: "Na verdade, dever-se-ia dizer que uma pessoa 'está esquizofrênica', e não que ‘é esquizofrênica” (p. 208).

Da literatura examinada, observa-se que o trabalho de Nise da Silveira dialoga com diferentes temáticas, como a arte, a política, a terapia ocupacional, a psicologia junguiana, a reforma psiquiátrica. Entretanto, não há produção que desenvolva possíveis paralelos entre o trabalho da psiquiatra e a psicologia fenomenológico-existencial. Também observa-se o interesse pelo resgate histórico e conceitual do trabalho de Nise da Silveira, vista como pioneira de práticas atuais voltadas à atenção em saúde mental. Seu pioneirismo refere-se a diferentes características de seu trabalho: forma de tratamento, com "emoções de lidar"; concepção de psicopatologia como "modos de ser"; livre expressão artística e o estabelecimento de vínculo afetivo para o tratamento. Porém, percebe-se que não há estudos empíricos que discutam o trabalho da psiquiatra nas práticas atuais. Para Melo (2001b, 2007), deve-se ter cautela em relação a atribuições acríticas sobre o pioneirismo de Nise da Silveira. Melo (2007) sugere estudar em que medida teoria e prática de Nise da Silveira condizem com o pioneirismo atribuído a ela, devendo se prestar atenção ao discurso e prática da psiquiatra, com suas consonâncias e contradições em relação à reforma psiquiátrica.

Inicia-se o discurso através das práticas atuais com o objetivo de retornar às origens. Dessa maneira, temos o seguinte esquema: as práticas hegemônicas da contemporaneidade são naturalizadas; as práticas contestatórias são excluídas do campo do saber; o passado é visto como reservatório de santos e/ou heróis; e, finalmente, há um retorno às práticas atuais, consideradas como destino inevitável (Melo, 2007, p. 110).

Melo (2007) aponta, nesse sentido, para o cuidado de não homogeneização de discursos: Nise da Silveira tinha uma abordagem mais clínica e privilegiava a expressão de si, enquanto os partidários da reforma psiquiátrica enfatizam os conceitos de contratualidade, cidadania e reabilitação social.

\section{A fenomenologia enquanto proposta de compreen- são do mundo}

Husserl (1859-1938) constitui a fenomenologia, com o propósito de fundamentar a filosofia, tornando-a uma ciência rigorosa (Husserl, 1910/1965). A princípio, pode-se dizer que a fenomenologia trata daquilo que se mostra à experiência do sujeito (Bello, 2006). Segundo Depraz (2007), o método fenomenológico é marcado por dois aspectos: o retorno à experiência do sujeito e o seu aspecto descritivo. Como ponto de partida, Husserl critica o contexto filosófico e científico da época, propondo-se a repensar os fundamentos das ciências humanas, questionando as ciências positivista, naturalista e empiricista.

Husserl, nas Conferências de Paris (1929/1992), expõe a fenomenologia como continuação e transformação das meditações cartesianas. Observa que o mundo se apresenta enquanto fenômeno, mas que isso não pode ser comprovação de sua existência. Nesse sentido, Husserl se contrapõe a Descartes. Para Husserl, o mundo se apresenta por meio da consciência, da experiência sensível, enquanto fenômeno. Tratar a experiência sensível do mundo como existente seria valorar o fenômeno que se apresenta, tratá-lo como real, psicofísico. "Tudo permanece como estava, só que não o assumo simplesmente como existente, mas abstenho-me de toda a tomada de posição ao ser e à aparência” (Husserl, 1929/1992, p. 15). Assim, influenciado por Brentano, Husserl reflete que o sujeito da consciência dos fenômenos não é neutro, como pensava o positivismo.

Nise da Silveira (1999) fala de modo crítico sobre Descartes, questionando a supervalorização do racional e dualismo mente-corpo, todavia, não se aprofunda nessas críticas. Husserl (1929/1992) está de acordo com Descartes ao compreender que o próprio sujeito, a partir de sua experiência sensível, conhece o mundo. Porém, se distancia dele no entendimento de que deve ser o ego transcendental, submetido à epoche, que conhece o mundo por meio de sua experiência no mundo e não tão somente o ego cogito. A partir da intencionalidade, Husserl discorda do subjetivismo transcendental de Descartes (Husserl, 1929/1992). Para Husserl, só há consciência a partir do sujeito da consciência e do objeto percebido, ao qual esse sujeito se remete. Nesse sentido, consciência é ato intencional, como consciência-de, não havendo consciência desvinculada do mundo. No ato de atribuir um sentido, objeto, sujeito e mundo se unificam por meio da intencionalidade da consciência (Forguieri, 2001).

O método fenomenológico consiste no retorno às coisas mesmas, ou seja, busca as essências dos fenômenos, que se apresentam à consciência do sujeito na sua experiência no mundo (Husserl, 1929/1992). A fenomenologia, assim, está fundada no sensível, mas sem se confundir com o mesmo (Forguieri, 2001). Este método se passa em dois momentos: intuição das essências e análise intencional. A primeira tarefa da fenomenologia é elucidar as essências dos fenômenos. Segundo Dartigues (2005), a essência pode ser descrita como o ser do fenômeno, o sentido ideal do fenômeno percebido, que permite identificá-lo. Para tal, deve-se realizar a epoche, a atitude de suspensão de juízos em relação ao fenômeno, colocando-os entre parênteses, sem contudo negá-los (Husserl, 1929/1992; Dartigues, 2005; Depraz, 2007). Abstendo-se dos pressupostos, torna-se possível realizar a descrição do fenômeno e de seus modos de manifestação. Busca-se, então, além das diferentes perspectivas e modos de expressão do fenômeno, o que permanece dele, sua essência. 
A análise intencional, segundo Dartigues (2005), se refere à análise da consciência do sujeito com o qual e a partir do qual se constitui o sentido do mundo, procura responder como é o sujeito que busca o sentido. O que Husserl - no esteio do pensamento de Brentano - acrescenta ao cogito cartesiano, é seu cogitatum, ou seja, o objeto intencionado, recolocando assim o sujeito em contato inalienável com o mundo. A análise intencional, pois, retira o sujeito da imanência, posicionando-o na transcendência do mundo.

Toda a análise intencional vai além da vivência momentânea e inclusamente dada da esfera imanente, e de modo tal que, ao descortinar potencialidades, patentes ingredientemente e à guisa de horizonte, realça multiplicidades de novas vivências, nas quais se torna claro o que só implicitamente se visava e já deste modo era intencional (Husserl, 1929/1992, p. 28).

Para Husserl, a fenomenologia deve fornecer fundamentos à psicologia, de modo a fazê-la cientificamente rigorosa. A psicologia fenomenológica deve ser uma ciência descritiva, isenta de juízos e preconceitos do fenômeno observado (Forguieri, 2001), para, a partir da vinculação com o objeto, aproximar-se de sua essência, daquilo que é universal e necessário (Depraz, 2007).

\section{Modos de ser e emoção de lidar: a proposta feno- menológica de Nise da Silveira}

De modo a iniciar a pesquisa por referências primárias de Nise da Silveira e outras referências secundárias, tomamos como ponto de partida a obra de Arruda (1995) - Resumo histórico da psiquiatria brasileira - na qual o autor traça um histórico da psiquiatria brasileira e cita o trabalho desenvolvido por Nise da Silveira no campo da terapia ocupacional e reabilitação como um dos progressos de sua época; e o Dicionário Biográfico da Psicologia no Brasil, no qual Melo (2001a) faz breve descrição sobre Nise da Silveira e referencia 16 publicações da psiquiatra. A partir dessas obras iniciou-se busca por mais referências sobre Nise da Silveira. Foi possível acessar ao todo 13 referências primárias, dentre elas livros, artigos e entrevistas e mais sete referências secundárias, sendo seis livros e uma revista (Arruda, 1995; Bezerra, 1995; Melo, 2001a; Mello, 2005; Melo \& Rodrigues, 2006; Psique Especial Ciência \& Vida, 2008; Mello, 2009b).

A literatura primária que será discutida refere-se à coletânea de entrevistas organizada por Mello (Encontros, 2009a), na qual Nise da Silveira, em diferentes momentos de sua vida, expõe sua prática, a Entrevista com Nise da Silveira (Leal, 1994), a coletânea de cartas Viagem a Florença: cartas de Nise da Silveira a Marco Lucchesi (Lucchesi, 2003) e algumas das obras de Nise da Silveira, entre livros e artigos: Terapêutica Ocupacional: Teoria e Prática (1966), Considerações teóricas e práticas sobre ocupação terapêutica (1952), Experiência de arte espontânea com esquizofrênicos num serviço de terapia ocupacional (Silveira \& Le Gallais, 1957), Jung: vida e obra (1968), Imagens do Inconsciente (1981), Casa das Palmeiras: a emoção de lidar (1986), Um homem em busca de seu mito (1989b), Cartas a Spinoza (1999), 40 anos do Museu de Imagens do Inconsciente (1992a), O mundo das imagens (1992b). Não foi possível acessar seis bibliografias primárias referenciadas por Melo (2001a): Silveira (1926, 1962, 1970, 1980, 1989a, 1998). Trata-se de obras que não compõem a bibliografia mais citada nas referências secundárias sobre Nise da Silveira.

Observa-se que as obras que Nise da Silveira deixou como legado tem um enfoque eminentemente prático, que delineiam contornos teóricos de seu trabalho (Silveira, 1966, 1986, 1992b). Além disso, ela publica apenas mais tarde obras que versam sobre seu trabalho; por exemplo, publica livro sobre a Casa das Palmeiras apenas 30 anos após sua inauguração (Silveira, 1986). A própria psiquiatra afirma que este seria um dos aspectos negativos do seu trabalho, a maneira quase empírica pelo qual foi realizado (Silveira, 1966).

As entrevistas com Nise da Silveira, que representam o material acessado mais rico sobre o trabalho dela, particularmente devido à presença de sua espontaneidade, relatam também experiências e encontros da psiquiatra com outros sujeitos e autores, que acabaram marcando sua vida e que contribuíram para o desenvolvimento de seu trabalho. Nise da Silveira valoriza tais vivências para aprimorar sua prática. Num exemplo, Nise da Silveira (em Mello, 2009a) comenta que Laura Brandão, esposa do militante comunista e alagoano Otávio Brandão, foi figura marcante em sua vida, pois havia lhe ensinado a ver beleza em tudo, inclusive nas mãos do trabalhador braçal, marcadas pelo seu trabalho. Esta questão foi considerada em seu trabalho com os esquizofrênicos. Bezerra (1995) e Melo (2001b) descrevem-na como uma pesquisadora que ao longo de sua trajetória profissional e pessoal se colocava numa atitude de aprendiz, não dogmática e persistente e que foi construindo sua obra ao longo de várias décadas de atendimentos e pesquisas.

Observa-se ainda nos relatos de Nise da Silveira, a influência de autores como Jung, Artaud e Spinoza, e de personagens com quem conviveu na academia de medicina, como seus vizinhos da rua Curvelo, na prisão e no hospício (Silveira, 1989, 1999; Bezerra, 1995; Melo, 2001b; Melo \& Rodrigues, 2006). Segundo Melo (2001b), Nise da Silveira e seu marido se relacionavam com personagens das artes, do sanitarismo e do estudo da Psicologia Analítica da época. Pode-se também perceber a influência de outros autores em suas obras, que tratavam da temática da expressão artística e da psicopatologia, como o psiquiatra alemão Hans Prinzhorn, que estudou obras plásticas de esquizofrênicos; Jean Dubuffet, com o conceito de arte bruta, ou o psiquiatra brasileiro Osório Cesar, pioneiro no uso da arte como recurso terapêutico. 
A partir de algumas de suas indicações, observa-se que ela teve contato direto com obras de autores da fenomenologia (Silveira, 1981; Melo, 2001 b), embora não tenha se aprofundado em seu estudo. Nise da Silveira, ao refletir sobre o trabalho desenvolvido com os esquizofrênicos no atelier de Pintura do Centro Psiquiátrico Pedro II, cita as obras de Karl Jaspers (Strindberg et Van Gogh); de Eugène Minkowski, pela obra Le Temps Vécu; e Maurice Merleau-Ponty, por sua Phénoménologie de la Perception e comenta sobre Ludwig Binswanger, todos autores de referência da psicopatologia fenomenológica (May, Angel \& Ellenberger, 1958/1967; Spiegelberg, 1972; Holanda, 2011). Além disso, em Considerações teóricas e práticas sobre ocupação terapêutica (1952), cita novamente Minkowski, ao fazer estudo sobre a história da terapêutica ocupacional. Também Jaspers é citado, em Cartas a Spinoza (Silveira, 1999). Percebe-se que Nise da Silveira faz pequenas considerações sobre os mesmos, sem maiores aprofundamentos. Tal fato mostra que a psiquiatra conhecia autores da fenomenologia, mas que eles não compunham maior influência em seu trabalho.

Os relatos de Nise da Silveira evidenciam a relação que fazia entre a prisão - com a qual conviveu por mais de um ano - e o hospital psiquiátrico, enredando a discussão sobre a reforma psiquiátrica (Bezerra, 1995; Mello, 2005; Melo \& Rodrigues, 2006), e levando-a a um questionamento sobre a alienação e a estigmatização promovida pelas duas instituições, aproximando-a sobremaneira dos escritos contemporâneos de Erving Goffman - particularmente em Manicômios, Prisões e Conventos (Goffman, 1961/1996) - quando este compara a instituição hospitalar aos conventos e às prisões, apontando-lhes as semelhanças enquanto instituições totalitárias com diversos mecanismos de mortificação e alheamento do sujeito. Porém, segundo Melo (2001b), mesmo que o trabalho de Nise da Silveira tenha sido influenciado por sua experiência na prisão, há exagero em relação ao que dizem sobre sua atuação na política nacional. Nise da Silveira se posiciona como simpatizante do movimento Basaglia, seu trabalho tem sincronia com o que fazem, entretanto a psiquiatra não se envolve diretamente com o movimento (Mello, 2009a).

A partir de sua vivência com os esquizofrênicos e de seu contato com práticas então comuns no Centro Psiquiátrico Nacional de Engenho de Dentro - como lobotomia, eletrochoque, coma insulínico, dentre outras e das quais discordava e se recusou a proceder, Nise da Silveira é realocada para a seção da terapêutica ocupacional do hospital (Mello, 2009a, 2009b). Segundo Nise da Silveira, a terapêutica ocupacional anterior a ela, se baseava em serviços monótonos e mecanizados que os doentes deveriam realizar para ajudar o hospital. "A inovação consistiu exatamente em abrir para eles o caminho da expressão, da criatividade, da emoção de lidar com os diferentes materiais de trabalho" (Silveira, citada por Mello, 2009a, p. 28). Observa-se que a terapêutica ocu- pacional desenvolvida por Nise da Silveira delineou-se como alternativa ao tratamento psiquiátrico vigente, do qual discordava (Silveira, 1986; Bezerra, 1995; Mello, 1995; Melo, 2001b).

Nise da Silveira ressalta que o hospital, ao invés de asilar o doente, deveria restabelecer as relações do mesmo com o meio, diminuindo também o número das reinternações em hospitais psiquiátricos (Silveira, 1966). Com esse objetivo funda, com Maria Stela Braga, Belah Paes Leme e Lígia Loureiro, a Casa das Palmeiras, descrita como “(...) um território livre, onde não há pressões geradoras de angústia, nem exigências superiores às possibilidades de respostas de seus frequentadores" (Silveira, 1986, p. 11). Para a psiquiatra, a meta do tratamento psiquiátrico não deveria ser a remoção de sintomas, mas a recuperação do indivíduo para a comunidade e, desse modo, a terapêutica ocupacional seria reconhecida como método terapêutico legítimo, não mais como uma prática auxiliar (Silveira, 1966).

Nise da Silveira não compreende que a reabilitação social do doente seja moldá-lo, tornando-o apto a um trabalho que lhe é entediante, sem sentido, porque senão ela mesma concordaria com a terapêutica ocupacional desenvolvida antes de suas atividades no hospital. Pelo contrário, sua concepção de terapêutica ocupacional para a reinserção social do doente enquanto trabalhador inclui justamente a realização de atividades que desenvolvam sua criatividade e prazer ao criar, características presentes nas atividades expressivas (Silveira, 1966, 1986). Assim, para a psiquiatra, a reabilitação por meio da terapêutica ocupacional não deve objetificar o doente, mas que ele desenvolva modos de lidar e manter seu equilíbrio psíquico e, assim, ter certa autonomia para decidir sobre seu futuro. É possível entender que para Nise da Silveira, a reabilitação do esquizofrênico envolva o desenvolvimento de estratégias de ser no mundo, a partir de seu modo de ser esquizofrênico. Segundo Mello (2009b), esse método terapêutico está em conformidade com a luta antimanicomial, quando propõe terapêutica fundada no exercício da cidadania.

Aquilo que se impõe à psiquiatria é uma verdadeira mutação, tendo por princípio a abolição total dos métodos agressivos, do regime carcerário, e a mudança de atitude face ao indivíduo, que deixará de ser o paciente para adquirir a condição de pessoa, com direito a ser respeitada (Silveira em Mello, 2005, p. 127).

Observa-se que Nise da Silveira constrói seus questionamentos sobre a psiquiatria tradicional a partir também de suas próprias vivências e experiências com os esquizofrênicos; ao invés de enxergá-los sob o crivo do diagnóstico previamente dado e restringir sua percepção sobre os mesmos, a psiquiatra constata que "o esquizofrênico" dos livros não condizia com aquele com quem convivia no hospital: pela psiquiatria tradicional, o es- 
quizofrênico, que não se utiliza racionalmente da fala, é colocado no lugar da "não-razão", sem considerar suas outras formas de linguagem. Nesse lugar da "não-razão", tudo o que ele expressa, é utilizado como justificativa de seu diagnóstico, como é o caso das produções criativas dos esquizofrênicos.

E assim aprendi outra lição, que desmentia o que afirmavam os livros de psiquiatria sobre os doentes mentais. Esses livros diziam que os esquizofrênicos eram indiferentes, sem afeto. Mas a doente que me levava o café da manhã em meu quarto, quando soube de minha prisão, não ficou indiferente. Eu não entendia nada o que ela falava, mas ela estava entendendo o que se passava (Silveira em Mello, 2009a, p. 22).

A alteração no comportamento da doente mostra que ela foi afetada pelo que acontecia, ou seja, que não é indiferente ao que se passa no meio. Entretanto, a psiquiatria clássica desconsideraria isso, analisando unicamente que a mesma apresentava uma fala desconexa, ininteligível, reforçando seu diagnóstico de esquizofrenia, de ruptura com o mundo. Em suas vivências, Nise da Silveira observa que não é só pela linguagem verbal que o contato com o outro pode ser estabelecido e que, em especial ao esquizofrênico, isso deve ser atentado. "Aí comecei a achar que o estudo da psiquiatria era insatisfatório. Porque estuda-se principalmente uma listagem de sintomas (...). Mas acontecem coisas de grande complexidade que escapam a essa listagem básica" (Silveira em Mello, 2009a, p. 96).

O que podemos destacar disso tudo é uma significativa proximidade das posições de Nise da Silveira em relação a boa parte da tradição da psicopatologia fenomenológica. Por um lado, a psiquiatra concordaria, por exemplo, com Maldiney (2007) - importante representante da psiquiatria fenomenológica contemporânea - quando este coloca que o verdadeiro "assunto" da psicopatologia é o sujeito humano, e que a colocação da prioridade na "doença" - ou na "patologia" - não consegue alcançar a complexidade dessa experiência. Ademais, esta posição retoma o caminho da fenomenologia, caracterizada como uma busca pela compreensão dos "modos de ser" da psicopatologia, ou do "mundo-vida" dos pacientes (Holanda, 2011); resgatando-lhes a voz e a cidadania, suas realidades vivenciais e pessoais (Ionescu, 1994). Convém destacar que essas posições são compatíveis - senão marcadas pela trajetória inaugurada por Karl Jaspers (1913/1987), desde sua Psicopatologia Geral, quando afirmara a posição privilegiada do sujeito na relação.

No editorial intitulado "40 anos do Museu de Imagens do Inconsciente", Nise da Silveira (1992a) traça sua biografia, relatando momentos pessoais e já conhecidos de sua carreira que lhe foram significativos. Comenta que foi seu mestre de clínica médica que lhe ensinou a enxergar o paciente em sua totalidade.
Para ele, o doente estendido ali num leito de indigente do Hospital Santa Isabel não era uma máquina. Valladares nos ensinava uma semiologia minuciosa, na intenção que compreendêssemos a dinâmica dos sintomas. Dava-nos a visão do doente em sua totalidade de ser humano, e nunca de uma máquina, sobre a qual poderiam ser derramadas, ou introduzidas quantidades enormes de sustâncias químicas (Silveira, 1992a, p. 147).

Com esse intuito, Nise da Silveira, ao final de sua carreira, deixa de designar seus pacientes por esse nome: "Nada de pacientes! As pessoas" (Silveira em Mello, 2009a, p. 116), resgatando, assim, o sujeito que foi esquecido no hospital, e a humanidade que lhe é inerente. Vistos já alguns aspectos do trabalho de Nise da Silveira, é possível observar pontos de convergência com a fenomenologia, compreendendo-a enquanto fundamento, atitude; mesmo que a psiquiatra não tenha se proposto a seguir o método fenomenológico. Sua posição não era a de detentora de conhecimento e poder sobre seus pacientes, como se soubesse mais deles do que eles próprios. Ao contrário, é possível observar que Nise da Silveira adota postura de querer saber mais sobre a vivência do sujeito com esquizofrenia, a partir do que ele expressa e das formas como se expressa. Assim, mostra ter abertura para a experiência, adotando postura empática frente aos seus pacientes. Ao relatar que o esquizofrênico com quem convivia não condizia com o descrito nos livros de psiquiatria, observa-se que Nise da Silveira se coloca no movimento de abdicar da posição do saber, para observar seus pacientes enquanto fenômenos. Nesse sentido, é possível dizer que ela suspende suas teorias e preconceitos sobre a esquizofrenia, procurando primeiro compreender seus pacientes a partir da relação com os mesmos. Há, aqui, aquilo que se designa como a mudança da atitude natural para a atitude fenomenológica, num movimento de retorno às coisas mesmas.

Também desse modo, é possível observar que Nise da Silveira coloca a doença "entre parênteses" para compreender o sujeito que se apresentava a ela. Assim, ela afirma que a esquizofrenia é um dos modos de ser no mundo e percebe coisas antes não questionadas: a possibilidade do paciente se expressar por outros meios que não pela linguagem verbal e o desenvolvimento de uma terapêutica ocupacional, especialmente das atividades expressivas. A terapêutica de Nise da Silveira, em conformidade com uma abordagem fenomenológica, antes de mais nada, aceita o esquizofrênico como sujeito que existe por meio da esquizofrenia, como um dos modos possíveis de ser no mundo e que isso não é algo necessariamente a ser corrigido, mas que deve ser respeitado e trabalhado, segundo as possibilidades do próprio sujeito.

Nesta direção, caminha ao lado da psiquiatria fenomenológica, naquilo que aponta Escoubas (2006): "Se só há psicose de um existente, a psicose se compreende so- 
mente à luz do existir e, inversamente, enquanto catástrofe do existir, a psicose permite o vir à luz desse existir" (p. 81). Ou, naquilo que designa Binswanger, como sendo a tarefa da psiquiatria fenomenológica, qual seja, a de elucidação fenomenológica da existência como ser-no-mundo, como estrutura existencial de seus modos de ser nesse mundo (Spiegelberg, 1972).

Outro aspecto ressaltado pela psiquiatra é a que o conhecimento científico não é suficiente para atuar adequadamente na terapêutica ocupacional. "A pessoa humana de cada um, a sensibilidade, a intuição, são qualidades preciosas" (Silveira, 1966, p. 39). Nesse sentido, a autora mostra que a academia, ao privilegiar o racional em relação às outras qualidades humanas, não forma bons profissionais. "Quantas vezes falei aos estagiários dizendo-lhes para substituir os manuais da psiquiatria pela leitura da obra de Machado de Assis, onde encontrariam a alma humana estudada em espantosa profundidade" (Silveira, em Bezerra, 1995, p. 165). A postura de Nise da Silveira não é de negar a importância dos conhecimentos teóricos e técnicos. Pelo contrário, ela apenas lembra que esse conhecimento não deve enrijecer a prática da terapêutica frente ao doente, que é, sim, um sujeito. O terapeuta deve se utilizar da intuição para atender seu paciente, ao invés de se enrijecer em protocolos técnicos. "A sensibilidade para captar desejos no canto dos olhos de esquizofrênicos é muito mais importante que conhecimentos técnicos. Se as duas coisas estiverem juntas evidentemente será o ideal" (Silveira, em Bezerra, 1995, p. 172).

Assim, Nise da Silveira não fala em técnicas em seu trabalho: "A minha técnica é a ausência de técnica, nunca propor coisas antigas, é propor tudo novo, é tratá-los de uma maneira absolutamente igual. Eu os trato como eu trato a você, não tenho medo deles." (Silveira, em Mello, 2009 a, p. 70) A intervenção teria como pressuposto trabalhar com pessoas, e não com alguém anteriormente taxado como doente. Desse modo, sua prática se desenvolve segundo o modo como o doente se apresenta, segundo sua singularidade.

O modo como Nise da Silveira conhece o fenômeno da esquizofrenia, reconhecendo as vivências relatadas por seus pacientes e considerando suas próprias vivências com os mesmos, também têm ressonância com a posição fenomenológica. Nesta direção, afirma que o afeto não deve ficar a nível teórico, mas estar presente na relação terapêutica. Observa-se que Nise da Silveira adota uma relação dialógica com seus pacientes esquizofrênicos. Ela sabe que não há sujeito neutro frente ao outro, pelo contrário, que o sujeito deve estar implicado na relação. Assim, Nise da Silveira adota atitude compreensiva, abstendo-se de julgamentos a priori e entendendo seu paciente enquanto sujeito único e em sua totalidade, ao invés de vê-lo como mais uma amostra de esquizofrenia.

Nise da Silveira também dialoga com uma postura fenomenológica quando fala de intuição, que considera uma qualidade essencial para o terapeuta, reiterando que este não deve estar enrijecido em sua prática, mas encaminhá-la segundo o sujeito único que está a sua frente. O protocolo, então, dependendo de como é entendido, pode obscurecer a visão do terapeuta em relação ao sujeito que se apresenta, enrijecer sua prática, diminuir a espontaneidade do trabalho que o terapeuta deveria assumir frente ao ser singular que está à sua frente. A psiquiatra, observando as atividades expressivas tornarem-se terapêuticas reconhecidas nas clínicas psiquiátricas, adverte para que a atividade não tenha como fim a mera produção material, técnica, mas que tenha como propósito, a partir de seu arcabouço teórico, o desenvolvimento do sujeito que realiza a atividade (Melo, 2001b). Para ela, os monitores das oficinas de terapêutica ocupacional são essenciais para o bom desenvolvimento terapêutico. Eles ocupam a função de catalisador das emoções na atividade realizada pelo esquizofrênico (Silveira, 1966). Observa-se que, para Nise da Silveira, a relação que o monitor estabelece com o doente deve ser natural, enxergando a pessoa com quem ele trabalha, estando com ele na realização de sua atividade, tendo o afeto na relação, de modo a construir laços de confiança (Silveira, 1966, 1986; Bezerra, 1995). "O que existe lá é naturalidade. O monitor está ali, não dá ordens e trata cada um de forma personalizada. É fundamental uma abordagem não ortodoxa da loucura” (Silveira em Mello, 2009a, p. 121).

Outro instrumento de Nise da Silveira para o trabalho com os doentes foram os animais, chamados de coterapeutas. Segundo Nise da Silveira (em Mello, 2009a), o animal se torna o elo entre o doente e o mundo.

Empiricamente ficou evidente que o cão podia tornar-se um elo intermediário nas relações entre o terapeuta e o esquizofrênico. Com efeito, o cão sendo incondicional nos seus afetos apresenta-se como objeto estável por excelência para relacionamento. Além disso, transborda do calor que os materiais de trabalho não podem oferecer (Silveira, 1966, p. 52).

Mais uma vez, pode-se dizer que Nise da Silveira dialoga com uma perspectiva fenomenológica. Em atitude de abertura para o novo, constata também que os animais podem ser pontes da relação dos seus pacientes com mundo. Ao suspender seus pressupostos sobre a esquizofrenia, Nise da Silveira atenta para a relação que seus pacientes estabelecem com o mundo e justamente aí percebe o potencial dos animais como instrumento terapêutico.

A loucura é mais uma temática explorada por Nise da Silveira. Para a psiquiatra, a loucura pode ser definida, resgatando o pensamento de Antonin Artaud, como os inumeráveis estados de ser do sujeito (Silveira, 1989b), compreendendo que as classificações da psiquiatria não conseguem dar conta da multiplicidade de vivências da loucura, definindo, então, a esquizofrenia não como uma 
doença, mas como estado do ser. Nise da Silveira observa ainda que a esquizofrenia é um fenômeno objetivo, real para quem a experiencia.

Uma coisa é o observador, situado do lado de fora, registrar elementos que emergem aqui e acolá, originários de uma trama em desdobramento na escuridão inconsciente. Outra coisa, completamente diferente, será vivenciar essa própria trama. Densa objetividade para quem as experimenta, essas estranhas vivências internas apresentam-se àqueles que estão do outro lado do muro como inconscientes fantasias (Silveira, 1989b, p. 11).

O objeto da fenomenologia é tudo o que se apresenta enquanto fenômeno. Para o esquizofrênico, o delírio se constitui como objeto real, que é percebido. Nise da Silveira não ignora tal aspecto, partindo da vivência do seu paciente, e da intenção de elucidar os sentidos desses sintomas. A partir de estudo sobre Artaud, o qual escreve sobre suas vivências psicóticas, Nise da Silveira se questiona sobre os tratamentos existentes e sobre a possibilidade de pensar a terapêutica a partir dos recursos que o sujeito dispõe (Silveira, 1989b). Assim, Nise da Silveira coloca em questão se não é pela religião que Artaud consegue lidar com a esquizofrenia. Nesse sentido, Nise da Silveira se interroga: "Visando fim idêntico - a reconstrução da personalidade - a medicina aplicou-lhe séries de eletrochoques. Por que nos falta coragem para comparar os dois métodos?” (Silveira, 1989b, p. 21). Desse modo, Nise da Silveira compreende que a religião ocupa um lugar na manutenção do equilíbrio do modo de ser esquizofrênico de Artaud e respeita a possibilidade disso enquanto terapêutica.

Nise da Silveira observa que qualitativamente, os fenômenos das doenças do espírito não diferem dos mecanismos da vida psíquica normal (Silveira, 1966; Mello, 2005), ou seja, a fronteira entre o normal e o patológico é tênue. Considerados doentes ou não, todos os sujeitos vivem esses diferentes modos de ser. Assim, o trabalho de Nise da Silveira se constitui em mostrar que é possível ser louco e artista, ao mesmo tempo (Mello, 2005). Muitos pacientes que frequentavam o atelier de pintura da seção de terapêutica ocupacional foram reconhecidos pela qualidade de seus trabalhos no meio artístico. Desse modo, Nise da Silveira desconstrói a cisão entre normal e patológico, resgatando o sujeito que está por detrás do diagnóstico.

Um dos grandes interesses filosóficos da psiquiatra foi o pensador holandês Baruch Spinoza (1632-1677), que utiliza para compreender a loucura (Silveira, 1999; Mello, 2009a). No livro Cartas a Spinoza (Silveira, 1999), ela diz:

Todas as coisas existentes são modos, isto é, modificações, afecções da substância, e não podem ser concebidas sem a substância ou fora da substância, sua causa imanente. A existência dos modos é precária. Existem ou deixam de existir, enquanto é eterna a substância (p. 24).

Nesse sentido, ela entende que a esquizofrenia seja um dos modos de ser possíveis do sujeito e que esses estados podem se modificar.

A psiquiatra também analisou a relação entre o racional e o imaginário e suas consequências ao estudo das produções criativas dos esquizofrênicos (Silveira, 1999). "Compreendo que a ordem do imaginário e a alta ordem do pensamento racional são diferentes. E também que o imaginário não seria redutível a termos racionais. Aí está o nervo da questão" (Silveira, 1999, p. 93). A questão que Nise da Silveira levanta refere-se ao modo "racionalizante" pelo qual a psiquiatria tradicional e psicologia olhavam a produção desses doentes e que, desse modo, impossibilitava o desenvolvimento dos mesmos (Leal, 1994; Silveira, 1999).

No livro Terapêutica Ocupacional - Teoria e prática (Silveira, 1966), relata os avanços na consolidação da terapêutica ocupacional no serviço nacional de doenças mentais. Neste texto - e mais em duas publicações acerca do Museu Imagens do Inconsciente (Silveira, 1986, 1992a) - Nise da Silveira assinala a dificuldade de disseminar e aprimorar as atividades dos centros de terapêutica ocupacional e reabilitação, devido à falta de interesse do meio psiquiátrico (Arruda, 1995). A psiquiatra também coloca tal questão para os profissionais do campo da psicoterapia: "Parece-me que a psicoterapia concede ainda muito pouco valor à ação orientada com objetivo terapêutico" (Silveira, 1986, p. 16). Seu questionamento coloca relevância sobre a expressão criativa, que segundo a psiquiatra, permanece intocada na condição dita esquizofrênica, sendo o meio pelo qual o esquizofrênico possuiria maior facilidade de se comunicar, e que poderia ser explorada para o desenvolvimento de seu contato com o mundo, mas que continuamente é desconsiderada pela psiquiatria tradicional (Bezerra, 1995; Mello, 2005; Mello, 2009a). Ao invés disso, coloca-se a racionalidade e sua expressão na linguagem verbal, como sendo o único meio de intervenção com o doente. "Normalmente, as linhas de psicologia e psiquiatria querem reduzir as vivências emocionais ao verbo. Acreditam que se não há interação verbal não pode haver cura. O processo do Engenho de Dentro mostra o contrário” (Silveira em Mello, 2009 a, p. 131).

Nise da Silveira distingue quatro grupos de atividades realizadas na Seção de Terapêutica Ocupacional e Reabilitação do hospital: atividades que envolvam o esforço característico do trabalho, atividades expressivas, atividades recreativas e atividades culturais (Silveira, 1966). O tipo de atividade a ser realizada depende do estado em que o paciente se encontra e de seus interesses. O trabalho dela tornou-se conhecido justamente pelas atividades expressivas, que incluem modelagem, gravura, escultura em madeira, música, dança, mími- 
ca, teatro e, em especial, a pintura; trata-se de atividades que permitem a expressão espontânea do sujeito, de suas emoções e afetos, por meio de símbolos (Silveira, 1966, 1986).

Deste modo, Nise da Silveira elege a expressão criativa como meio apropriado de intervenção com os esquizofrênicos. "O que cura, fundamentalmente, é o estímulo à criatividade” (Silveira em Mello, 2009a, p. 115). A imaginação, presente na expressão criativa, respeita a experiência vivida pelo doente, pois não visa fazer uma leitura racional do que é expresso por ele (Silveira, 1986). Pela linguagem verbal ser, por excelência, instrumento do pensamento lógico, das elaborações do raciocínio, quando o sujeito adoece, o pensamento passa a ser concreto, acontece sob a forma de imagens e o sujeito não mais consegue se comunicar pela fala (Silveira, 1966; Melo, 2001b). Assim, a utilização da imaginação dá voz ao esquizofrênico, por ser uma forma de linguagem que ele tem mais desenvolvida, possibilitando o desenvolvimento de contato entre ele e o mundo (Silveira, 1966, 1986, 1999; Bezerra, 1995).

Em Experiência de arte espontânea com esquizofrênicos num serviço de terapia ocupacional (Silveira, 1957) - no qual a autora reflete sobre a potencialidade terapêutica da atividade expressiva, a partir de um estudo de caso -, ela explica que o esquizofrênico, por meio da expressão criativa, constrói imagens, nas quais seu inconsciente se apresenta em forma de símbolos e mitos. Desta forma, a expressão criativa tem importância tanto ao estudo dos processos psicopatológicos, quanto terapêuticos (Silveira, 1966).

Em seu trabalho com esquizofrênicos, Nise da Silveira percebeu que as imagens produzidas por seus pacientes se configuravam em forma de mandalas, caracterizando uma busca por reorganização psíquica, por equilíbrio, pela auto-cura (Silveira, 1957; Mello, 2009a, 2009b). Para Jung, a mitologia constitui a linguagem inata da psique em sua estrutura profunda (Silveira, 1968; Bezerra, 1995). É a partir dessa questão, na possibilidade de acessar o mundo do psicótico por meio da atividade criativa, na qual a mitologia se expressa, que Nise da Silveira se envolve com a psicologia analítica e com o pensamento de C.G.Jung, e, a partir disso, compreende a teoria como instrumento de trabalho, que deve ter como fim uma prática que faça sentido (Leal, 1994; Melo, 2001).

Eu fui levada a ter esse contato empiricamente. Muita gente acha que apliquei Jung assim... eu fui levada. Mas pode-se dizer que cada teoria científica é completamente válida. Uns se ajeitam com um instrumento de trabalho e outros com outro. Para mim, realmente a psicologia junguiana foi instrumento muito produtivo de trabalho (Silveira em Mello, 2009a, p. 55).

Parte então da observação para, posteriormente, procurar na teoria ferramentas que possibilitem o desenvol- vimento do seu trabalho. "De fato, à observação clínica atenta junto o esforço do pensamento na medida de minhas possibilidades, aceito as intuições, mas recorro à reflexão que as examina. E a presença da emoção é permanente" (Silveira em Melo, 2001, p. 37). Observa-se então outra possibilidade de diálogo da autora com a fenomenologia, por tomar como ponto de partida a observação dos fenômenos, com juízos em suspenso, para só então, olhá-los sob a perspectiva da teoria. Nise da Silveira adota tal posicionamento; lida com a teoria como ferramenta de acesso ao sujeito.

Ainda ligando-se ao pensamento de Jung, Nise da Silveira compreende que há uma divisão entre o mundo interno e o mundo externo do sujeito (Mello, 2009a). O médico que queira estabelecer relação com o doente através de uma linguagem comum deve ter conhecimento da linguagem mítica que, segundo ela, é a linguagem pela qual o inconsciente, o mundo interno do doente se expressa e possibilitar espaço para tal (Silveira, 1966, 1986; Mello, 2005, 2009a). Segundo suas observações, as imagens do inconsciente, produzidas por meio de símbolos, possuem capacidade transformadora do sujeito, ao dar forma às emoções do sujeito (Silveira, 1957, 1966, 1992a). Assim, a criatividade é entendida como fonte de reestruturação psíquica, permitindo que o sujeito dê formas e organize seu mundo interno.

Nesse sentido, uma das observações da psiquiatra é que o sujeito, na atividade expressiva, pode apresentar como mecanismo de defesa, uma tendência à abstração (Silveira, 1957, 1981). Em contraposição a esta tendência, percebeu ainda que seus pacientes, durante o processo terapêutico, passavam a figurar suas pinturas (Silveira, 1957, 1981). A psiquiatra refere-se a isso como uma tendência ao naturalismo, como uma tentativa de reintegração do sujeito com o mundo. Assim, Nise da Silveira mostra seu interesse em estudar o mundo interno do doente, sem desprezar o mundo externo, em contraposição à psiquiatria clássica, que considera apenas o mundo externo (Mello, 2009a). Por meio da teoria de Jung, Nise da Silveira considera que no processo psicopatológico, a sombra, os conteúdos reprimidos ou não desenvolvidos pela consciência, tomam conta do consciente do sujeito (Silveira, 1968; Melo, 2001b). Desse modo, a terapêutica da expressão criativa deve confrontar a consciência com a experiência da sombra, considerando, então, a multiplicidade da própria existência e os "estados de desmembramento do ser” do estado patológico. Assim, o processo terapêutico deve resgatar tal movimento.

O modo como Nise da Silveira trabalha por meio da expressão criativa de seus pacientes também apresenta convergências com uma perspectiva fenomenológica. Seu foco é o sujeito e não a doença, pensando, então, terapêuticas a partir da relação de seu paciente com o mundo. Assim as produções expressivas de seus pacientes evidenciam sujeitos criativos. A atividade artística é muito utilizada como meio de vislumbrar o sujeito da psicopa- 
tologia. Entretanto, a abordagem fenomenológico-existencial também permite a compreensão da atividade artística como facilitadora do desenvolvimento do sujeito. Assim, o estudo na abordagem fenomenológica-existencial resgata a subjetividade da psicopatologia, ao invés de encobri-la na estrutura discursiva. Nise da Silveira retira o papel de diagnóstico da expressão criativa e mostra seu potencial transformador.

A psiquiatra, ao final de sua vida, nomeia esse trabalho como "emoção de lidar", referência à experiência de um dos seus pacientes ao pintar (Bezerra, 1995; Melo, 2001b). Não se interessou pelo termo arteterapia, pois não achava ser sua função qualificar o trabalho de seus pacientes como artísticos ou não. Além disso, também disse não utilizar mais a nomenclatura "terapia ocupacional" para designar seu trabalho, pois esse termo fazia referência à antiga terapêutica dos hospitais psiquiátricos, que se tratava de trabalho para ajudar na economia do hospital, ao invés de visar o tratamento dos sujeitos hospitalizados (Leal, 1994; Mello, 2009a).

Refletir sobre a relação do trabalho de Nise da Silveira com a psicologia fenomenológico-existencial, também requer pensar a relação de Jung - um autor que é referência para a psiquiatra -, com a fenomenologia. A aproximação entre os dois autores se estabelece na postura que adotam em seus métodos, mesmo apresentando radicais filosóficos diferentes (Brooke, 2008; Lima \& Diogo, 2009). Jung, embora cite esporadicamente a fenomenologia, a tem como um recurso crítico a uma abordagem excessivamente teórica (como algumas de suas críticas a Freud) ou coloca sua posição como um "ponto de vista fenomenológico" em contraste com perspectivas centradas sobre "questões de substância” (Spiegelberg, 1972, p. 131). Mesmo não assumindo uma posição husserliana - Husserl não é citado em suas obras completas, embora cite Heidegger e Jaspers -, para Jung:

(...) manter uma postura fenomenológica significava valorizar a experiência, compreendida como a experiência vivida pelo indivíduo. Tal posição era central à sua crítica à teorização freudiana. $\mathrm{O}$ apego de Freud à sua teoria sexual, bem como sua preocupação com a elaboração de um sistema metapsicológico coerente e fechado, o teria afastado de uma atitude inicialmente empírica e descritiva em direção à construção de uma ciência da interpretação (Lima \& Diogo, 2009, p. 17).

Da mesma forma que Jung, observa-se que Nise da Silveira apresenta relações semelhantes com a fenomenologia: não se aproxima da mesma sob o ponto de vista dos radicais filosóficos de Husserl, mas se aproxima em relação a sua postura frente aos seus pacientes, no sentido de valorizar a experiência vivida pelos mesmos e seu método de trabalho. Neste sentido, promove uma aproximação com a fenomenologia, da mesma maneira que diversas outras abordagens clínicas se designam como tais, pela postura, acolhimento à relação, respeito pela subjetividade, etc. A psiquiatra desenvolveu seu trabalho, primando pela observação e pela experiência direta com seus pacientes, colocando a teoria numa posição secundária. Além disso, procura colocar entre parênteses o conhecimento estabelecido então, através da teoria, para poder compreender seus pacientes. Deve-se salientar que é justamente tal aspecto, que permite Nise da Silveira pensar novas alternativas terapêuticas. Porém, da mesma forma que Jung se afasta da fenomenologia, dividindo mundo interno e externo (Brook, 2008; Lima \& Diogo, 2009), observa-se que Nise da Silveira também o faz. Em suas obras, utiliza recorrentemente o conceito de inconsciente e faz separação entre mundo interno, das representações e externo, do real.

\section{Considerações finais}

Nise da Silveira desenvolve um enfoque eminentemente prático, no qual mostra a relação intrínseca entre trabalho e vida. As referências primárias e secundárias de Nise da Silveira, aqui analisadas, abordam tal questão, ressaltando sua atitude não dogmática e que parte das problemáticas que surgem de sua realidade para o desenvolvimento de seu trabalho. Mesmo não se envolvendo diretamente com os autores da fenomenologia, é possível afirmar que Nise da Silveira apresenta uma atitude fenomenológica, tendo em vista sua concepção de sujeito e sua postura frente a ele, muito próxima do que Binswanger designa por uma "fenomenologia antropológica”, “(...) que se preocupa com a totalidade do ser humano, na sua normalidade e anormalidade, enquanto um ser que se experiencia em relação com o mundo" (Holanda, 2014, p. 89).

Observa-se que Nise da Silveira valorizava a experiência prática, compreendendo que a teoria não deveria anteceder a observação do sujeito em seu contexto, de modo que fosse possível enxergar o sujeito que se apresenta, para além de sua psicopatologia. Nesse sentido, percebe-se que Nise da Silveira faz o movimento de suspender a teoria para ver o sujeito em sua relação com o mundo, que se apresentava a ela. Nesta atitude, a psiquiatra observa a importância da empatia, a potencialidade terapêutica do trabalho com animais e da expressão criativa, não mais vista como instrumento diagnóstico, mas de expressão e transformação do sujeito. Também assim que compreende a esquizofrenia como um dos modos possíveis de ser no mundo e que a reabilitação deve envolver o desenvolvimento de estratégias do sujeito como um ser no mundo, a partir de seu modo de ser. Enfim, pode-se dizer que Nise da Silveira fundamenta sua terapêutica no reconhecimento do humano.

Porém, percebe-se que Nise da Silveira se afasta da fenomenologia, enquanto proposta de Husserl de radicais filosóficos e método rigoroso. Como seu mestre Jung, Nise 
da Silveira apresenta radicais filosóficos divergentes da fenomenologia e método fenomenológico proposto por Husserl. Deve-se lembrar que Nise da Silveira acessou obras de alguns autores da fenomenologia, mas que estes não foram o foco principal de sua atenção.

O pensamento de Nise da Silveira mostra-se ainda muito atual. Sua terapêutica, que não privilegiava a fala, a perspectiva de trabalho multidisciplinar e a criação de uma clínica psiquiátrica em regime aberto também demonstram sua inovação. Entretanto, como Melo (2007) adverte, deve-se ter cautela em intitular a psiquiatra como pioneira das práticas atuais, sem antes refletir cuidadosamente sobre a qualidade dos serviços atuais em saúde mental.

Por fim, é interessante salientar o caráter de inacabamento proposto pela própria fenomenologia, que permite apreendê-la como possibilidade. Nise da Silveira demonstra adotar tal atitude, não se fechando em si, mas, pelo contrário, por sua constante abertura à experiência. A dificuldade no acesso à literatura concernente à vida e obra de Nise da Silveira certamente respondem pelas limitações desse trabalho, mas espera-se que este sirva de estímulo para novas pesquisas e novos resgates dessa importante personagem da nossa história; e que a miríade de temas trabalhados por ela, igualmente sirva de aberturas a novas perspectivas no campo da clínica.

\section{Referências}

Arruda, E. (1995). Resumo histórico da psiquiatria brasileira. Rio de Janeiro: UFRJ.

Bello, A. A. (2006). Introdução à fenomenologia (J. Garcia \& M. Mahfoud, Trad.). São Paulo: EDUSC.

Bezerra, E. (1995). A trinca do Curvelo: Manuel Bandeira, Ribeiro Couto e Nise da Silveira. Rio de Janeiro: Topbooks.

Brooke, R. (2008). Jung and Phenomenology. Pittsburgh: Trivium Publications.

Castro, E. D., \& Lima, E. M. F. A. (2007). Resistência, inovação e clínica no pensar e no agir de Nise da Silveira. Interface - Comunicação, Saúde, Educação, 11(22), 365-376.

Dartigues, A. (2005). O que é fenomenologia? (M. J. J. G. Almeida, Trad.). São Paulo: Centauro (Original publicado em 1972).

Depraz, N. (2007). Compreender Husserl (F. Santos, Trad.) Rio de Janeiro: Vozes.

Dias, P. B. (2003). Arte, loucura e ciência no Brasil: as origens do Museu de Imagens do Inconsciente. Rio de Janeiro.

Escoubas, E. (2006). Henri Maldiney. Em P. Cabestan (Org.), Introduction à la Phénoménologie Contemporaine (p. 69-82). Paris: Ellipses Éditions.

Estrada, I. M. D. (1995). Nise da Silveira. Cientistas do Brasil: depoimentos. São Paulo: Sociedade Brasileira para o Progresso da Ciência.
Figueira, E., Amarante, M. C., \& Belancieiri, M. F. (2007). O pioneirismo como espelho: o uso da arte por psicólogos em ambientes hospitalares. Psicologia Hospitalar, 5(1), 100-113.

Forguieri, Y. C. (2001). Psicologia fenomenológica: fundamentos, método e pesquisa. São Paulo: Pioneira Thomson Learning.

Frayze-Pereira, J. A. (2003). Nise da Silveira: imagens do inconsciente entre psicologia, arte e política. Estudos Avançados (USP), 17(49), 197-208.

Goffman, E. (1996). Manicômios, Prisões e Conventos. São Paulo: Perspectiva (Original publicado em 1961).

Guimarães, J., \& Saeki, T. (2007). Sobre o tempo da loucura em Nise da Silveira. Ciência \& Saúde Coletiva, 12(2), 531-538.

Holanda, A. F. (2011). Gênese e Histórico da Psicopatologia Fenomenológica. Em V. Angerami-Camon (Org.), Psicoterapia e Brasilidade (p. 115-160). São Paulo: Cortez Editora.

Holanda, A. F. (2014). Fenomenologia e Humanismo. Reflexões Necessárias. Curitiba: Editora Juruá.

Husserl, E. (1965). A Filosofia como Ciência de Rigor. Coimbra: Atlântida (Original publicado em 1910).

Husserl, E. (1992). Conferências de Paris (A. Fidalgo \& A. Morão, Trad.). Lisboa: Edições 70 (Original publicado em 1929).

Ionescu, S. (1994). Catorce Enfoques de la Psicopatologia. México: Fondo de Cultura Econômica.

Jaspers, K. (1987). Psicopatologia Geral. Rio de Janeiro: Atheneu (Original publicado em 1913).

Karniol, I. G. (2003). Psicanálise em psicóticos. Revista Brasileira de Psicanálise, 37(4), 1087-1104.

Leal, L. G. P. (1994). Entrevista com Nise da Silveira. Psicologia, Ciência e Profisssão, 14(1-3), 22-27.

Lima, A. A., \& Diogo, J. C. K. (2009). Reflexões sobre a afinidade de Jung com a fenomenologia. Revista da Abordagem Gestáltica, 15(1), 13-20.

Lucchesi, M. (2003) (Org.). Viagem a Florença: cartas de Nise da Silveira a Marco Lucchesi. Rio de Janeiro: Rocco.

Maldiney, H. (2007). L'existant. Em P. Fédida \& J. Schotte (Orgs), Psychiatrie et Existence (p. 23-46). Paris: Éditions Jêrome Millon.

May, R., Angel, E., \& Ellenberger, H. F. (1967) (Eds.). Existencia. Madrid: Editorial Gredos S.A. (Original publicado em 1958).

Mello, L. C. (2005). Imagens do Inconsciente. Catálogo. Curitiba: Museu Oscar Niemeyer.

Mello, L. C. (Org.). (2009a). Encontros - Nise da Silveira. Ed. Azougue.

Mello, L. C. (2009b). Nise da Silveira: caminhos de uma psiquiatra rebelde. Catálogo. Curitiba: Museu Oscar Niemeyer. 
Melo, H. P., \& Rodrigues, L. M. C. S. (2006). Pioneiras da Ciência no Brasil. São Paulo: Sociedade Brasileira para o Progresso da Ciência.

Melo, W. (2001a). Silveira, Nise Magalhães da (1905-1999). Em R. H. de F. Campos (Org.), Dicionário bibliográfico da psicologia no Brasil (p. 356-358). Coleção Pioneiros da psicologia brasileira. Rio de Janeiro: Imago; Brasília: CFP.

Melo, W. (2001b). Nise da Silveira (Coleção Pioneiros da Psicologia Brasileira). Rio de Janeiro: Imago.

Melo, W. (2007). Maceió é uma cidade mítica: o mito da origem em Nise da Silveira. Psicologia USP, 18(1), 101-124.

Melo, W. (2010a). Nise da Silveira, Fernando Diniz e Leon Hirszman: política, sociedade e arte. Psicologia USP, 21(3), 633-652.

Melo, W. (2010b). A etimologia inspirada: a busca da língua original através da semiosis introvertida. Estudos e Pesquisas em Psicologia (UERJ), 10(3), 865-881.

Motta, A. A. (2005). Nise da Silveira: 100 anos de emoções de lidar. Junguiana, 23, 7-21.

Psique Especial Ciência \& Vida. (2008). Psiquiatria no BrasilNise da Silveira. Ano III, 07.

Silveira, N. da (2002). Biografia. Nise da Silveira. Psicologia, Ciência e Profissão, 22(1), 137.

Silveira, N. da (1952). Considerações teóricas e práticas sobre ocupação terapêutica. Revista Medicina e Cirurgia (194), 1-10.

Silveira, N. da, \& Le Gallais, P. (1957). Experiência de arte espontânea com esquizofrênicos num serviço de terapia ocupacional. Revista Brasileira de Saúde mental, 3, 37-47.

Silveira, N. da (1966). Terapêutica ocupacional: Teoria e prática. Rio de Janeiro: Casa das Palmeiras.

Silveira, N. da (1968). Jung: vida e obra. Rio de Janeiro: Paz e Terra.

Silveira, N. da (1981). Imagens do Inconsciente. Rio de Janeiro: Alhambra.

Silveira, N. da (Org.). (1986). Casa das Palmeiras: a emoção de lidar. Rio de Janeiro: Alhambra.

Silveira, N. da (1989b). O homem em busca de seu mito. Em M. Lucchesi (Org.), Artaud: a nostalgia do mais (p. 9-23). Rio de Janeiro: Alhambra.

Silveira, N. da (1992a). 40 anos do Museu de Imagens do Inconsciente. Jornal Brasileiro de Psiquiatria, 41(4), p. 147.

Silveira, N. da (1992b). O mundo das imagens. São Paulo: Ática.

Silveira, N. da (1999). Cartas a Spinoza (2. ed.). Rio de Janeiro: Francisco Alves.

Spiegelberg, H. (1972). Phenomenology in Psychology and Psychiatry. A historical introduction. Evanston: Northwestern University Press.

\section{Bibliografia não-consultada}

Andrade, L. Q. (1993). Terapias expressivas: uma pesquisa de referenciais teórico-práticos. Tese de Doutorado, Instituto de Psicologia, Universidade de São Paulo, São Paulo.

Brasil. Ministério da Saúde. Secretaria-Executiva. Subsecretaria de Assuntos Administrativos. Coordenação-geral de Documentação e Informação. Centro Cultural da Saúde. (2007 a). Nise da Silveira: vida e obra: catálogo de vídeos. Brasília: Ministério da Saúde.

Brasil. Ministério da Saúde. Secretaria-Executiva. Subsecretaria de Assuntos Administrativos. Coordenação-geral de Documentação e Informação. Centro Cultural da Saúde. (2007 b). Nise da Silveira: vida e obra: cartilha de monitoria. Brasília: Ministério da Saúde.

Dionísio, G. H. (2012). O antídoto do mal: crítica de arte e loucura na modernidade brasileira. Rio de Janeiro: Fiocruz.

Silveira, N. da (1926). Ensaios sobre a criminalidade das muIheres na Bahia. Salvador: Imprensa Oficial.

Silveira, N. da (1962). C. G. Jung e a psiquiatria. Revista Brasileira de Saúde mental, 7.

Silveira, N. da (1970). Perspectiva da Psicologia de C. G. Jung. Revista Tempo Brasileiro, 21/22.

Silveira, N. da (1980). Museu de Imagens do Inconsciente. Em M. Pedrosa (Org.), Museu de Imagens do Inconsciente. Rio de Janeiro: Funarte/ Instituto Nacional de Artes Plásticas.

Silveira, N. da (Org.). (1989a). A farra do boi: do sacrifício do touro na antiguidade à farra do boi catarinense. Rio de Janeiro: Numen.

Silveira, N. da (1998). Gatos: a emoção de lidar. Rio de Janeiro: Léo Christiano.

Karoline Stoltz Schleder - Graduada em Psicologia pela Universidade Federal do Paraná e Graduanda de Pintura pela Escola de Música e Belas Artes do Paraná.

E-mail: ss.karoline@hotmail.com

Adriano Holanda - Psicólogo, Doutor em Psicologia e Docente do Departamento de Psicologia e do Programa de Pós-Graduação (Mestrado) em Psicologia da Universidade Federal do Paraná. Coordenador do Laboratório de Fenomenologia e Subjetividade (LabFeno). Endereço Institucional: Depsi/UFPR, Praça Santos Andrade, 50, Sala 215 (Ala Alfredo Buffren). Curitiba/PR. CEP: 80.020.300.

E-mail:aholanda@yahoo.com

Recebido em 11.03.2014 Primeira Decisão Editorial em 10.07.2014 Segunda Decisão Editorial em 13.09.2014 Aceito em 04.12.2014 